\title{
Abdome agudo como manifestação inicial de melanoma metastático. Relato de caso
}

\author{
Acute abdomen as initial manifestation of metastatic melanoma \\ Marcos Aurélo Pessoa Barros, ACBC-CE ; Nathalia Siqueira Robert de Castro²; Thiago Camelo Mouräo³
}

\section{INTRODUÇÃO}

C om origem nos melanócitos, células pigmentadas, derivadas da crista neural e normalmente presentes na epiderme, o melanoma pode acometer todas as idades. Embora a grande maioria dos melanomas tenha sua origem na pele, outros locais de início incluem a mucosa oral e anogenital, o esôfago, as meninges e o olho'.

O melanoma é uma das afecções causadoras de metástase para o trato gastrointestinal. Os sintomas podem incluir dor abdominal, disfagia, obstrução, hematêmese e melena. Os sítios primários mais comuns são: tronco $(40 \%)$, membros (22\%), cabeça e garganta (15\%). Cerca de $16 \%$ dos casos apresentam sítio primário desconhecido. Os locais de metástases mais encontrados em autópsias são: pele e tecido subcutâneo (75\%), pulmão (70\%), fígado $(68 \%)$, intestino delgado (58\%), pâncreas (53\%), coração $(49 \%)$, cérebro (39\%) e baço $(36 \%)^{2,3}$.

O período médio da sobrevivência para pacientes com metástases não viscerais é de 7,2 meses, porém cai para 2,4 meses quando existe metástase hepática, associada ou não ao acometimento de outros órgãos ${ }^{3}$.

\section{RELATO DO CASO}

JMBS, masculino, pardo, 36 anos de idade, natural e procedente de Fortaleza (CE), com queixa de dor no membro inferior esquerdo, lombalgia e constipação há uma semana. Procurou o Serviço de Clínica Médica da Santa Casa da Misericórdia de Fortaleza, sendo internado para investigação com suspeita de hepatopatia crônica, devido à presença de múltiplos nódulos hepáticos ao ultrassom abdominal. Ao exame físico, referia dor à palpação superficial em hipocôndrio direito e epigástrio. O paciente realizou endoscopia digestiva alta (EDA) que evidenciou gastrite erosiva leve de antro. Apresentando-se em bom estado geral, recebeu alta para continuação da investigação clínica no ambulatório. Retornou após uma semana com abdome agudo, sendo levado ao centro ci- rúrgico para lapatoromia exploratória de urgência. Foi constatada a presença de múltiplos nódulos enegrecidos no fígado (Figura 1), em alças intestinais e no mesentério (Figura 2), difusamente distribuídos, impossibilitando qualquer procedimento cirúrgico. Foi realizada então a biópsia das lesões. Não foi identificada na pele nenhuma lesão melanocítica visível. O paciente teve rápida progressão do quadro, morrendo dois dias depois. O resultado da biópsia

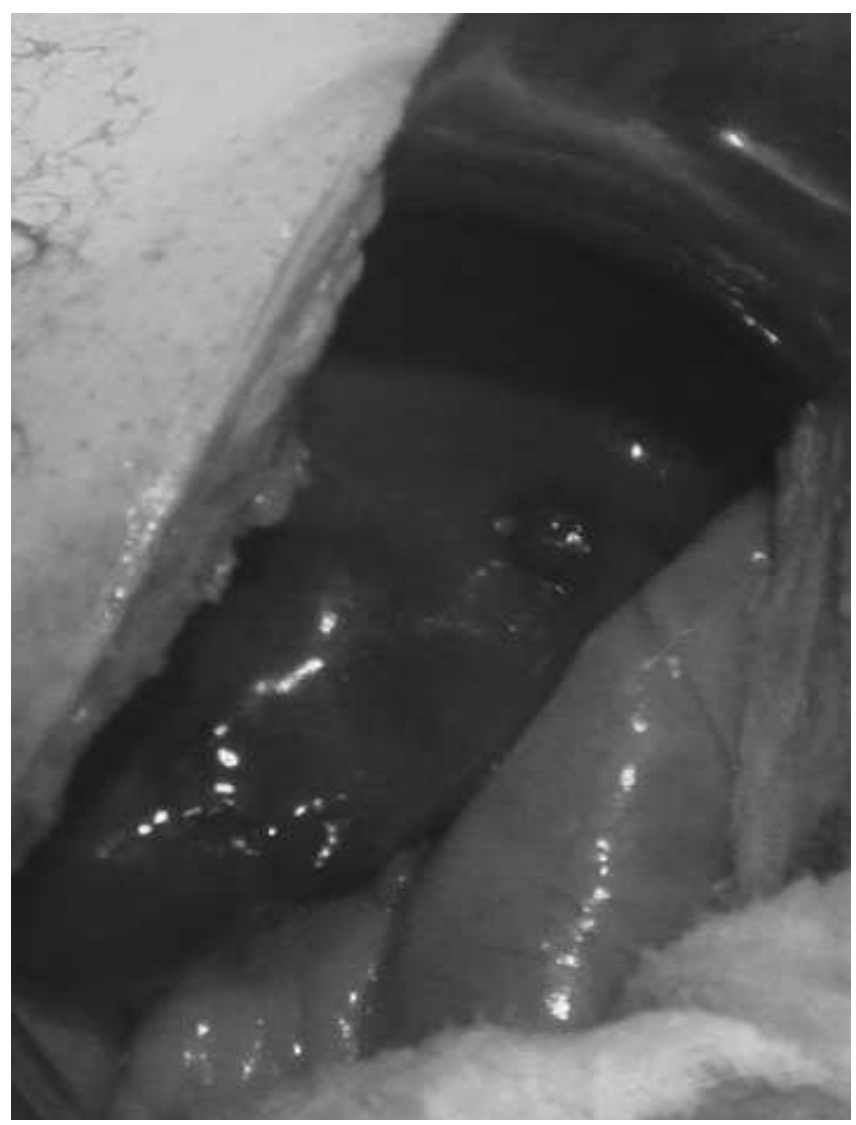

Figura 1 - Metástase hepática. Foto obtida durante o procedimento cirúrgico no qual foi realizada a biópsia da lesão hepática, visualizada na figura na forma de múltiplos nódulos escuros (melanocíticos).

Trabalho realizado no Serviço de Cirurgia Oncológica do Hospital Santa Casa da Misericórdia de Fortaleza, CE - Brasil.

1. Cirurgião Oncológico do Hospital Universitário Walter Cantídio - Universidade Federal do Ceará - CE-BR; 2. Residente do Serviço de Clínica Médica do Hospital Universitário Walter Cantídio - Universidade Federal do Ceará; 3. Residente do Serviço de Cirurgia Geral do Hospital de Clínicas de Ribeirão Preto - Universidade de São Paulo. 


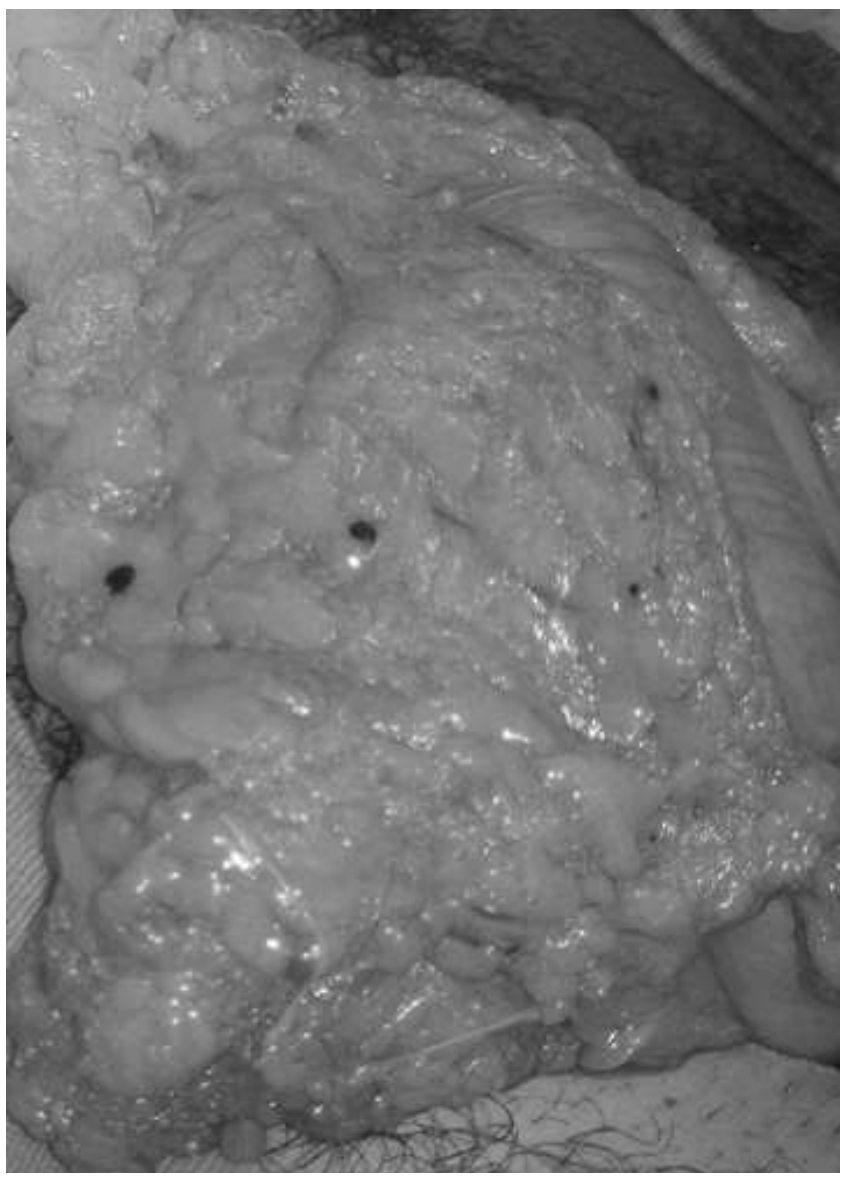

Figura 2 - Metástase mesentérica. Foto ilustrando as múltiplas lesões melanocíticas encontradas no mesentério do paciente durante a laparotomia exploratória (pontos negros, semelhantes a nevos cutâneos).

evidenciou nas quatro peças enviadas para análise (nódulos mesentérico, do mesocólon, hepático e peritoneal) implantes metastásticos de melanoma maligno.

\section{DISCUSSÃO}

O diagnóstico de melanoma é facilmente confirmado após a análise histológica da lesão, porém se torna difícil quando o paciente é portador de metástases à distância. Isso provavelmente é devido ao fato do intervalo de tempo entre o diagnóstico da lesão primária e o aparecimento das metástases ser muito longo, dificultando ao examinador relacionar a queixa atual com a história pregressa do paciente. Klaase et al. chegaram a um intervalo médio de três anos entre o surgimento do melanoma primário e de suas metástases em um estudo com 30 pacientes portadores de melanoma maligno ${ }^{3}$.

As metástases do melanoma maligno podem ocorrer muitos anos após a apresentação da lesão primária inicial. Ocasionalmente, representam a primeira evidência da doença ou ocorrem mesmo na ausência de um tumor primário clínico detectável.

No caso relatado, o paciente apresentou-se inicialmente com doença metastática disseminada para o fígado, mensentério e alças intestinais, não sendo levantada a hipótese diagnóstica ao pré-operatório em decorrência desta forma clínica de apresentação inicial do melanoma metastático.

A incidência de metástases gastrointestinais é provavelmente muito maior do que a sugerida pelos estudos atuais. A discrepância relativamente elevada entre a incidência baixa de metástases gastrointestinais clinicamente diagnosticadas e a incidência em autópsias é presumivelmente relacionada à ocorrência de sintomas abdominais inespecíficos durante a vida ${ }^{4}$.

O plano terapêutico para pacientes com metástases de melanoma é difícil, já que o tratamento cirúrgico, radioterápico e quimioterápico, sozinhos ou combinados, não conduzem ao aumento da sobrevida em longo prazo. Sendo assim, o tratamento atual é em maior parte paliativo ${ }^{5}$.

A decisão de realizar a ressecção do melanoma metastático deve seguir os princípios gerais que se aplicam ao paciente com metástases de outros tipos de tumores primários. A ressecção paliativa deve ser realizada somente com o intuito de aliviar sintomas, como obstrução, hemorragias ou dor, já que não há ganho significativo na sobrevida. O sucesso no alcance dos objetivos estará dependente da localização metastática, da morbidade do procedimento, do curso da doença e da capacidade de comunicação entre o cirurgião, o paciente e a família ${ }^{4}$.

A radiologia tem um papel importante na detecção inicial de metástases gastrointestinais. Reenfatizando, as metástases gastrointestinais podem representar a manifestação inicial do melanoma maligno e que estes podem ocorrer na ausência de uma lesão primária clínica óbvia².

\section{Agradecimentos}

À Santa Casa da Misericórdia de Fortaleza - CE.

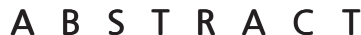

The malignant melanoma is a relatively common neoplasia, with origin generally in the melanocytics cells in the skin, but with presentation of other possible primary lesions, being presented in this, a case witnessed of liver and mesentery metastases with unknown primary sites.

Key words: Abdomen, acute. Neoplasms, unknown primary. Liver neoplasms. Neoplasm metastasis. Melanoma. 


\section{REFERENCIAS}

1. Cotran RS, Kumar V, Robbins SL. Robbins: Patologia estrutural e funcional. $7^{a}$ ed. Rio de Janeiro: Guanabara Koogan; 2005.

2. Liang KV, Sanderson SO, Nowakowski GS, Arora AS. Metastatic malignant melanoma of the gastrointestinal tract. Mayo Clin Proc. 2006:81(4):511-6.

3. Klaase JM, Kroon BB. Surgery for melanoma metastatic to the gastrointestinal tract. Br J Surg. 1990;77(1):60-1. Apud Ornellas LC, Lanzoni VP, Toledo CF. Malignant melanoma with liver and spleen metastases: case report. Sao Paulo Med J. 2000;118(2):536.

4. Allen PJ, Coit DG. The surgical management of metastatic melanoma. Ann Surg Oncol. 2002;9(8):762-70.

5. Wood TF, DiFronzo LA, Rose DM, Haigh PI, Stern SL, Wanek L, et al. Does complete resection of melanoma metastatic to solid intraabdominal organs improve survival? Ann Surg Oncol. 2001;8(8):658-62.
Recebido em 23/05/2007

Aceito para publicação em 30/06/2007

Conflito de interesse: nenhum

Fonte de financiamento: nenhuma

\section{Como citar este artigo:}

Barros MAP, Castro NSR, Mourão TC. Abdome agudo como manifestação inicial de melanoma metastático. Relato de caso. Rev Col Bras Cir. [periódico na Internet] 2013;40(3). Disponível em URL: http:// www.scielo.br/rcbc

\section{Endereço para correspondência:}

Marcos Aurélio Pessoa Barros

E-mail: maureliopbarros@terra.com.br 